\title{
COMPARISION OF CEMENTED VERSUS UNCEMENTED HEMIARTHOROPLASTY OF THE HIP.
}

1. MBBS, FCPS (Orth), Assistant Professor Department of Orthopaedics Independent Medical College, Faisalabad, Pakistan

2. MBBS, FCPS (Orth) Senior Registrar Department of Orthopaedics Children Hospital,

The Institute of Child Health, Lahore.

3. MBBS, FCPS (Orth), Consultant Orthopaedic Surgeon Govt. General Hospital, Samanabad, Faisalabad.

4. Pharm-D, M.Phil, PhD Scholar Govt. College University, Faisalabad.

Correspondence Address: Dr. Hafiz Salman Saeed MBBS, FCPS (Orth),

Assistant Professor of Orthopaedics Independent Medical College,

Faisalabad, Pakistan.

hafizsalman167@gmail.com

Article received on: 06/04/2019

Accepted for publication: 20/06/2019

Received after proof reading: $25 / 06 / 2019$

\begin{abstract}
Hafiz Salman Saeed ${ }^{1}$, Farhad Alam², Muhammad Yousaf ${ }^{3}$, Iqra Fayyaz ${ }^{4}$
\end{abstract}
ABSTRACT... The objective of this study was to compare the mean residual pain after cemented versus uncemented hemiarthroplasty of hip. Study Design: Randomized Controlled Trial. Setting: Orthopaedic Department, Allied Hospital, Faisalabad. Period: September 2016 to October 2017. Materials and Methods: Total 150 patients were admitted in orthopedic Department of Allied Hospital Faisalabad according to inclusion \& exclusion criteria. After taking informed written consent, all patients were divided into two groups randomly. Cemented hemiarthroplasty was done in Group A patients and uncemented hemiarthroplasty was done in group B patient. All procedures were done by surgeon who has minimum $5 y$ rs post fellowship experience. Monthly Follow up was done and residual pain was noticed at the end of $6^{\text {th }}$ month. All the data was analyzed by using SPSS version 20.0. Results: In this study, in Group-A the patients between $65-75$ years of age were $57.33 \%(n=43)$ and between $76-85$ of age were $42.67 \%(n=32)$. In Group B the patients between $65-75$ years of age were $56 \%$ $(n=42)$ and between $76-85$ years were $44 \%(n=33)$. The mean+sd was calculated and it is $73.49+4.99$ years in Group-A patients and $73.73+4.74$ years in Group-B patients. In Group A, males were $61.33 \%(n=46)$ and female were $38.67 \%(n=29)$. In Group B, males were $57.33 \%$ $(n=43)$ and female were $42.67 \%(n=32)$. When we compared the residual pain after cemented versus uncemented hemiarthroplasty of the hip, it shows $1.69+0.35$ in Group-A patients and $2.62+0.30$ in Group-B patients. When we calculated p-value it was 0.0001 showing a significant difference. Conclusion: It is concluded that residual pain in cemented hemiarthroplasty is lower than uncemented hemiarthroplasty.

Key words: Cemented, Hemiarthroplasty, Intracapsular Hip Fractures, Residual Pain, Uncemented.

Article Citation: Saeed HS, Alam F, Yousaf M, Fayyaz I. Comparision of cemented versus uncemented hemiarthoroplasty of the hip. Professional Med J 2019; 26(7):1057-1061. DOI: 10.29309/TPMJ/2019.26.07.3527

\section{INTRODUCTION}

A hip fracture is the most devastating \& challenging consequence of osteoporosis. The number of hip fractures are increasing in elderly people and major challenge for healthcare and economy. ${ }^{1}$ The chosen approach has benefited as a factor that may reduce the complication rate $\&$ enhances the speed of recovery after surgery. This helps the surgeons to continue to develop and remodel surgical techniques and approach. ${ }^{2}$

The option of hip hemiarthroplasty is superior and long lasting to internal fixation for displaced neck of femur fracture enabling earlier mobility, less chances of revision surgery and better outcome in terms of function at one year. ${ }^{3}$ The choice of implant and whether implant is cemented or uncemented remains controversial. ${ }^{4}$ Cementless implants are good for young patient because they have good bone stock and revision surgery is easy. On the other hand, cementing the femoral component does not necessarily increase the outcome. ${ }^{5}$ Although cemented implant given more secure fixation and results in less residual pain and better functional outcome. However, the insertion of cement into femur may complicate the operation and increase the risk of cardiovascular collapse. ${ }^{6}$ So uptil now six small randomized controlled trials involved 549 patients have been conducted in a Cochrane review on this subject. This showed that patient with cemented hemiarthroplasty have lesser pain and good functional outcome \& mobility than those of uncemented hemiarthoplasty. ${ }^{6}$ 
In another study, the mean residual pain after cemented hemiarthroplasty was $1.8+-1.2$ and after uncemented hemiarthroplasty was $2.4+-$ 1.4. ${ }^{7}$ The purpose of our study is to compare the residual pain in patients undergoing cemented hemiarthroplasty versus those undergoing uncemented hemiarthroplasty of the hip. So that based on these results, we adopt a method in our local population which helps us to reduce the residual pain after neck of femur fracture. The reduction in residual pain leads to early mobility, good functional outcome and early return to their routine activities. It overall improves socioeconomic status of the population

\section{VISUAL ANALOGUE SCALE}

A visual analogue scale (VAS) is a parameter to measure the intensity of pain and it has been widely used in diverse population. The VAS is a continuous scale that comprises of a horizontal line usually $10 \mathrm{~cm}(100 \mathrm{~mm})$ in length and it is anchored by verbal descriptors for the measurement of the intensity of pain. The scale is most commonly described as no pain (score of 0 ) and pain as bad or worst (score of 100).

\section{OBJECTIVES}

The objective of this study was to compare the mean residual pain after cemented versus uncemented hemiarthroplasty of hip.

\section{OPERATIONAL DEFINITIONS \\ Residual Pain}

It was measured by using visual analogue scale (VAS) at the end of $6^{\text {th }}$ month post-operatively.

\section{MATERIAL AND METHOD}

\section{Study Design}

Randomized Controlled Trials.

\section{Setting}

Orthopaedic Department, Allied Hospital, Faisalabad.

\section{Duration of Study}

September 2016 to October 2017.

\section{Sample Size}

The calculated sample size is 150 .

Sampling Technique

Non-probability, consecutive sampling.

\section{SAMPLING SELECTION}

Inclusion Criteria

- All intracapsular fractures of neck of femur. (Confirmed as breach in continuity of bone by X-ray)

- $\quad$ Patient age between 65-85 years

- Both genders

\section{Exclusion Criteria}

- Open fractures

- History of hip surgery

- Co-morbid diseases like uncontrolled diabetes mellitus (assessed on history)

- Non willing patients

\section{DATA COLLECTION AND ANALYSIS PROCEDURE}

Total 150 patients were admitted in orthopedic Department of Allied Hospital Faisalabad according to inclusion \& exclusion criteria. After taking informed written consent, all patients were divided into two groups randomly. Cemented hemiarthroplasty was done in Group A patients and uncemented hemiarthroplasty was done in group B patient. All procedures were done by surgeon who has minimum 5yrs post fellowship experience. Monthly Follow up was done and residual pain was noticed at the end of $6^{\text {th }}$ month. All the data was analyzed by using SPSS version 20.0 .

\section{RESULTS}

In this study, age distribution in Group- $A$, the patients between $65-75$ years of age were $57.33 \%$ $(n=43)$ and between $76-85$ of age were $42.67 \%$ $(n=32)$. In Group B the patients between 65-75 years of age were $56 \%(n=42)$ and between 76 85 years were $44 \%(n=33)$. The mean+sd was calculated and it is $73.49+4.99$ years in Group-A patients and $73.73+4.74$ years in Group-B patients (Table-I).

Gender distribution in Group A, males were $61.33 \%(n=46)$ and female were $38.67 \%(n=29)$. In Group B, males were $57.33 \%(n=43)$ and female were $42.67 \%(n=32)$ (Table-II).

When we compared the residual pain after cemented versus uncemented hemiarthroplasty 
of the hip, it shows $1.69+0.35$ in Group-A patients and $2.62+0.30$ in Group-B patients. When we calculated $p$-value it was 0.0001 showing a significant difference (Table-III).

Effect modifiers like age, gender and duration of fracture were controlled through stratification and post-stratification independent sample 't' test was applied to see their effect on outcome. P-value $\leq 0.05$ was considered as significant (Table-IV and V).

\begin{tabular}{|c|c|c|c|c|}
\hline \multirow{2}{*}{$\begin{array}{c}\text { Age } \\
\text { (years) }\end{array}$} & \multicolumn{2}{|c|}{$\begin{array}{c}\text { Group-A } \\
(n=75)\end{array}$} & \multicolumn{2}{|c|}{$\begin{array}{c}\text { Group-B } \\
(n=75)\end{array}$} \\
\hline & $\begin{array}{l}\text { No. of } \\
\text { Patients }\end{array}$ & $\%$ & $\begin{array}{l}\text { No. of } \\
\text { Patients }\end{array}$ & $\%$ \\
\hline $65-75$ & 43 & 57.33 & 42 & 56 \\
\hline $76-85$ & 32 & 42.67 & 33 & 44 \\
\hline Total & 75 & 100 & 75 & 100 \\
\hline Mean+SD & \multicolumn{2}{|c|}{$73.49+4.99$} & \multicolumn{2}{|c|}{$73.73+4.74$} \\
\hline \multicolumn{5}{|c|}{ Table-I. Age distribution $(n=150)$} \\
\hline \multirow{2}{*}{ Gender } & \multicolumn{2}{|c|}{$\begin{array}{c}\text { Group-A } \\
(n=75)\end{array}$} & \multicolumn{2}{|c|}{$\begin{array}{c}\text { Group-B } \\
(n=75)\end{array}$} \\
\hline & $\begin{array}{l}\text { No. of } \\
\text { Patients }\end{array}$ & $\%$ & $\begin{array}{l}\text { No. of } \\
\text { Patients }\end{array}$ & $\%$ \\
\hline Male & 46 & 61.33 & 43 & 57.33 \\
\hline Female & 29 & 38.67 & 32 & 42.67 \\
\hline Total & 75 & 100 & 75 & 100 \\
\hline
\end{tabular}

Table-II. Gender distribution $(n=150)$

\begin{tabular}{c|c|c|c|c|}
$\begin{array}{c}\text { Mean } \\
\text { Residual } \\
\text { Pain }\end{array}$ & \multicolumn{2}{|c|}{$\begin{array}{c}\text { Group-A } \\
(\mathbf{n = 7 5 )}\end{array}$} & \multicolumn{2}{c|}{$\begin{array}{c}\text { Group-B } \\
(\mathbf{n = 7 5 )}\end{array}$} \\
\hline & Mean & S.D & Mean & S.D \\
\hline & 1.69 & 0.35 & 2.62 & 0.30 \\
\hline
\end{tabular}

Table-III. Comparison of mean residual pain after cemented versus uncemented hemiarthroplasty of hip $(n=150) \quad P$ value $=0.0001$

\begin{tabular}{|c|c|c|c|c|c|}
\hline \multirow{2}{*}{$\begin{array}{c}\text { Age } \\
\text { (years) }\end{array}$} & \multicolumn{2}{|c|}{$\begin{array}{c}\text { Group-A } \\
\text { (n=75) }\end{array}$} & \multicolumn{2}{c|}{$\begin{array}{c}\text { Group-B } \\
(\mathbf{n = 7 5 )}\end{array}$} & P-Value \\
\hline & Mean & S.D & Mean & S.D & \\
\hline $65-75$ & 1.69 & 0.38 & 2.62 & 0.30 & 0.0001 \\
\hline $76-85$ & 1.70 & 0.32 & 2.61 & 0.31 & 0.0001 \\
\hline
\end{tabular}

Table-IV. Stratification for mean residual pain after cemented versus uncemented hemiarthroplasty of hip with regards to age $(n=150)$

\begin{tabular}{|l|c|c|c|c|c|}
\hline \multirow{2}{*}{ Gender } & \multicolumn{2}{|c|}{$\begin{array}{c}\text { Group-A } \\
(\mathbf{n = 7 5 )}\end{array}$} & \multicolumn{2}{c|}{$\begin{array}{c}\text { Group-B } \\
(\mathbf{n = 7 5 )}\end{array}$} & P-Value \\
\cline { 2 - 6 } & Mean & S.D & Mean & S.D & \\
\hline Male & 1.67 & 0.34 & 2.59 & 0.29 & 0.0001 \\
\hline Female & 1.73 & 0.37 & 2.65 & 0.31 & 0.0001 \\
\hline
\end{tabular}

Table-V. Stratification for mean residual pain after cemented versus uncemented hemiarthroplasty of hip with regards to gender $(n=150)$

\section{DISCUSSION}

Fractures of the neck of femur in old age patients either treated by Austin Moore Prosthesis, Thompson Prosthesis or Bipolar hemiarthroplasty. There are certain merits and demerits of cemented hemiarthroplasty versus uncemented hemiarthorplasty. Cemented implant gives more secure fixation and have reduction in residual pain and better functional outcome. However, the insertion of cement into the femur may increase the rate of complication and increase the risk of cardiovascular collapse.

The purpose of our study is to compare the mean residual pain after cemented versus uncemented hemiarthroplasty of hip in local population.

In this study, in Group-A, the patients between $65-75$ years of age were $57.33 \%(n=43)$ and between $76-85$ of age were $42.67 \%(n=32)$. In Group B the patients between $65-75$ years of age were $56 \%(n=42)$ and between $76-85$ years were $44 \%(n=33)$. The mean+sd was calculated and it is $73.49+4.99$ years in Group-A patients and $73.73+4.74$ years in Group-B patients. In Group A, males were $61.33 \%(n=46)$ and female were $38.67 \%(n=29)$. In Group B, males were $57.33 \%$ $(n=43)$ and female were $42.67 \%(n=32)$. When we compared the residual pain after cemented versus uncemented hemiarthroplasty of the hip, it shows $1.69+0.35$ in Group-A patients and $2.62+0.30$ in Group-B patients. When we calculated $p$-value it was 0.0001 showing a significant difference.

We compared our results with a previous study, where the mean residual pain after cemented hemiarthroplasty of hip was $1.8 \pm 1.2$ and after uncemented hemiarthroplasty was $2.4 \pm 1.4^{7}$, these findings are comparable with our results.

In Cochrane review, six small randomized controlled trials involved 549 patients have been conducted. This showed that patient with cemented hemiarthroplasty have lesser pain and good functional outcome \& mobility than those of uncemented hemiarthoplasty. ${ }^{6}$ They concluded that there was limited evidence that cemented hemiarthroplasty help in reduction of postoperative pain and better functional outcome. 
They concluded further randomized controlled trials were needed.

According to Australian National Joint Replacement Registry ${ }^{9}$, cemented Thompson prosthesis have lesser chance of revision surgery than uncemented Austin Moore prosthesis. For registered 15000 cases the revision surgery rate was markedly high $(p<0.001)$ for the uncemented implants. According to the Australian data they found that, the revision rate after four Years of surgery was $4 \%$ in cemented Thompson prosthesis versus $6 \%$ for uncemented Austin Moore prosthesis.

In 1982, Sonne-Holm, Walter and Jensen ${ }^{10}$, conduct a study in 112 patients to compare the results of cemented versus uncemented AustinMoore hemiarthroplasty. They found that there was no significant difference in mortality between the two groups. But the patient treated with cemented Austin Moore hemiarthroplasty have less pain and better functional outcome. Similar result was found in another study including 50 patients to compare a cemented versus uncemented bipolar hemiarthroplasty. ${ }^{11}$

Branfoot, also conduct a study in 91 patients, to compare a cemented Thompson prosthesis versus uncemented Thompson prosthesis. The result of the study was no significant difference in mortality in both groups. The mean pain score in 70 patients was high indicating more pain for the uncemented Thompson prosthesis. Although the result of cemented and uncemented Thompson prosthesis were not statistically significant.

In light of our results, the hypothesis that "cemented hemiarthroplasty is better than uncemented hemiarthroplasty of hip in terms of mean residual pain" is justified.

However, considering these results, the approach with lesser residual pain should be opted in our routine practice guidelines for these particular patients that may help to reduce their morbidity by early mobility and return to their routine activities.

\section{CONCLUSION}

It is concluded that residual pain in cemented hemiarthroplasty is lower than uncemented hemiarthroplasty.

Copyright $\odot 20$ June, 2019.

\section{REFERENCES}

1. Blankenbaker DG, De Smet AA. Hip injuries in athletes. Radiol Clin North Am. 2010; 48(6):1155-78.

2. Lindgren V, Garellick G, Kärrholm J, Wretenberg P. The type of surgical approach influences the risk of revision in total hip arthroplasty: A study from the Swedish Hip Arthroplasty Register of 90,662 total hipreplacements with 3 different cemented prostheses. Acta Orthop. 2012; 83(6):559-65.

3. Auffarth A, Resch H, Lederer S, Karpik S, Hitzl W, Bogner R, et al. Does the choice of approach for hip hemiarthroplasty in geriatric patients significantly influence early postoperative outcomes? a randomized-controlled trial comparing the modified Smith-Petersen and Hardinge approaches. J Trauma. 2011; 70(5):1257-62.

4. Taylor F, Wright M, Zhu M. Hemiarthroplasty of the hip with and without cement: a randomized clinical trial. J Bone Joint Surg Am. 2012; 94(7):577-83.

5. $\mathrm{Ng}$ ZD, Krishna L. Cemented versus cementless hemiarthroplasty for femoral neck fractures in the elderly. J Orthopaed Surg. 2014; 22(2):186-9.

6. Parker MJ, Gurusamy KS, Azegami S. Arthroplasties (with and without bone cement) for proximal femoral fractures in adults. Cochrane Database Syst Rev. 2010; 6:CD001706.

7. Parker MI, Pryor G, Gurusamy K. Cemented versus uncemented hemiarthroplasty for intracapsular hip fractures: a randomised controlled trial in 400 patients. J Bone Joint Surg. 2010; 92(1):116-22.

8. Parker MJ, Gurusamy K. Arthroplasties (with and without bone cement) for proximal femoral fractures in adults. (Cochrane Review). In: The Cochrane Library, Chichester: Wiley, 2006.

9. No authors listed. Australian Orthopaedic Association, National Joint Replacement Register. http://www.dmac. adelaide.edu.au/ aoanjrr/index.jsp (date last accessed 9 September 2009).

10. Sonne-Holm S, Walter S, Jensen JS. Moore hemiarthroplasty with and without bone cement in femoral neck fractures: A clinical controlled trial. Acta Orthop Scand 1982; 53:953-6. 
11. Dorr LD, Glousman R, Sew Hoy AL, Vanis R, Chandler R. Treatment of femoral neck fractures with total hip replacement versus cemented and noncemented hemiarthroplasty. J Arthroplasty 1986; 1:210-18.
12. Branfoot T, Faraj AA, Porter P. Cemented versus uncemented Thompson's prosthesis: $A$ randomised prospective functional outcome study. Injury 2000; $31: 280-1$.

\begin{tabular}{|c|l|l|l|}
\hline \multicolumn{4}{|c|}{ AUTHORSHIP AND CONTRIBUTION DECLARATION } \\
\hline Sr. \# & \multicolumn{1}{|c|}{ Author-s Full Name } & \multicolumn{1}{c|}{ Contribution to the paper } & Author=s Signature \\
\hline 1 & Hafiz Salman Saeed & $\begin{array}{l}\text { Manuscript writing \& statistical } \\
\text { analysis. } \\
\text { Intellectual concept of the } \\
\text { article \& manuscript writing. } \\
\text { Data collection \& data analysis. }\end{array}$ \\
\hline 3 & Farhad Alam & Muhammad Yousaf & Proof reading. \\
\hline 4 & Iqra Fayyaz & \\
\hline
\end{tabular}

